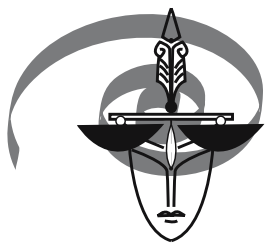

\title{
EUROPEAN
}

Volume $8 \cdot 2014 \cdot$ Number 1 (27)

DOI: 10.2478/ep-2014-0001

Jennifer M. C. Vendemia, Ph.D.

University of South Carolina

\section{fMRI as a Method of Detection of Deception: A Review of Experiences}

Key Words: fRMI, fRMI and detection in deception, new method of lie-detection, experimental lie detection

The first thing that individuals in the field of deception detection notice upon observing fMRI research conducted in a lab is how very different the experience is to the real world. In a typical fMRI experiment, a participant will lie in a scanner while performing a particular task (Figure 1).

In the earliest fMRI studies, participants watched patterns of grids, such as checkerboards, while scientists measured the output from the visual cortex. First, an MRI image is taken of the individual's brain which, like a fingerprint, has its own unique shape and size. Later, the voxels containing significant relative brain activity are overlaid on this image.

"vendemia@mailbox.ec.edu 


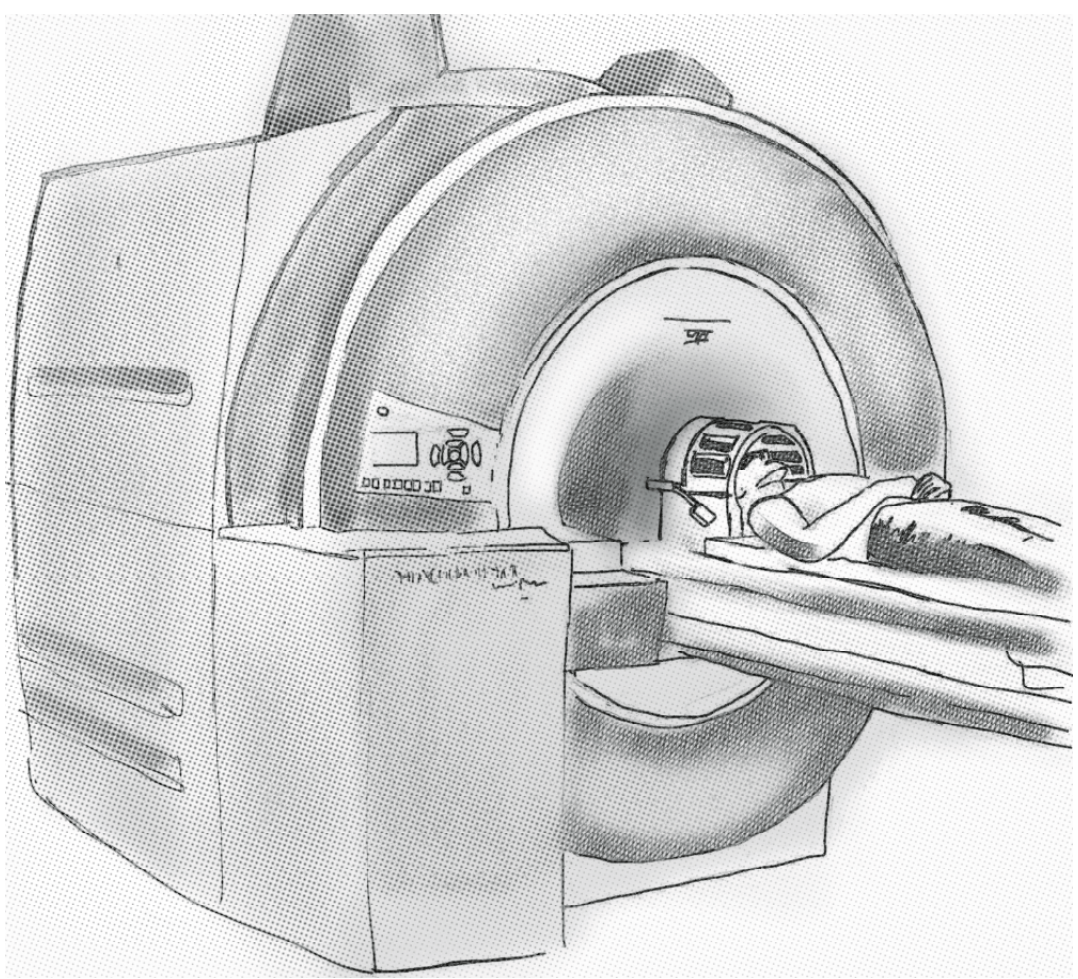

Figure 1: Participant resting on the table of an MRI, coils are placed around the head to measure the MRI signal. In a simple analogy, a camera captures the intensity and color of light to create an image. In an MRI, we use radio waves to excite the molecules in the brain and as the molecules return to rest, the released energy is captured by the MRI coils. Like the intensity and colors in a camera image, the energy from the various molecules in the brain show up with different intensities and contrasts (i.e. colors), creating an image.

Next, a series of low-resolution scans are recorded over time, some during one condition and others during a different condition (see Figure 2). For example, some scans might be taken while an individual is telling a lie, while others might be taken while an individual is telling the truth. The two sets of scans are later compared to see which areas are more active. When a humanbeing engages in a cognitive activity, such as subtraction, reading, or lying, various parts of the brain become active. Increased mental activity is associated with increased metabolic activity, and that metabolic activity results in an increase in blood flow to the area. The difference in blood flow between conditions is called "relative activity". For example, in order to compare relative activity between lie telling and truth telling, we compare the blood flow measured when a participant tells a lie to the blood flow measured when the same participant tells the truth. 


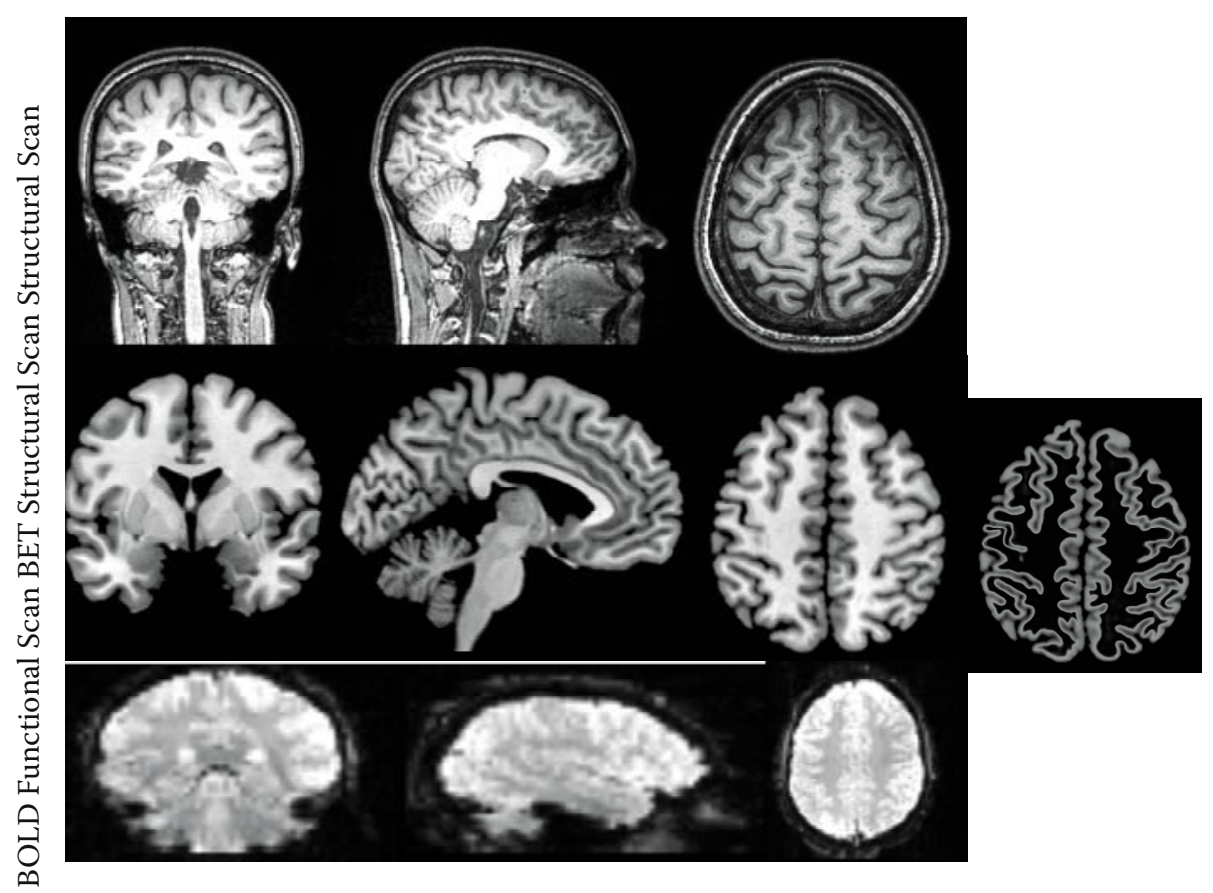

Figure 2. The first row depicts a complete T1 weighted scan. In the second row, the brain region has been extracted (BET) from the original scan. T1 weighted scans, a type of structural MRI, are designed to give the best possible picture of the brain's gray matter (see breakout). The third row shows one volume from a multivolume fMRI scan. Functional scans are made at much lower resolution than structural scans because time is a factor. Unlike a sMRI which can take as long as 12 minutes, an fMRI volume is measured in around 2-3 seconds. A second difference is that the functional BOLD scan is designed to measure blood oxygen.

Anyone who studies or practices in the field of deception detection will be familiar with this conundrum: How do we determine what a lie is? The fMRI offers no solution to the problem. An informal consensus among researchers is that the act of deception is not a unique cortical process, but the summation of many (some interchangeable) processes in the brain. For the purpose of discussing the how these processes might work, I have proposed a simple framework of the order of cognitive processes that occur when an individual hears a question and then responds deceptively (Figure 3).

Every person has a normal resting state, and pattern of physiological reactivity that is unique. Diverse factors such as physical health, emotional state, drug use, intelligence, and familial support systems all help to shape resting executive control. If a question is asked to which the person intends to lie, attention is directed to the question and cognitive resources are allocated. In addition, information is recalled that relates to the question as well as social 
decision making information. A decision is made to inhibit the truthful information and present the deceptive information. There is strong evidence that these processes are happening in parallel. For example, it is not always necessary to fully retrieve information from long-term memory before deciding to inhibit it and respond deceptively.

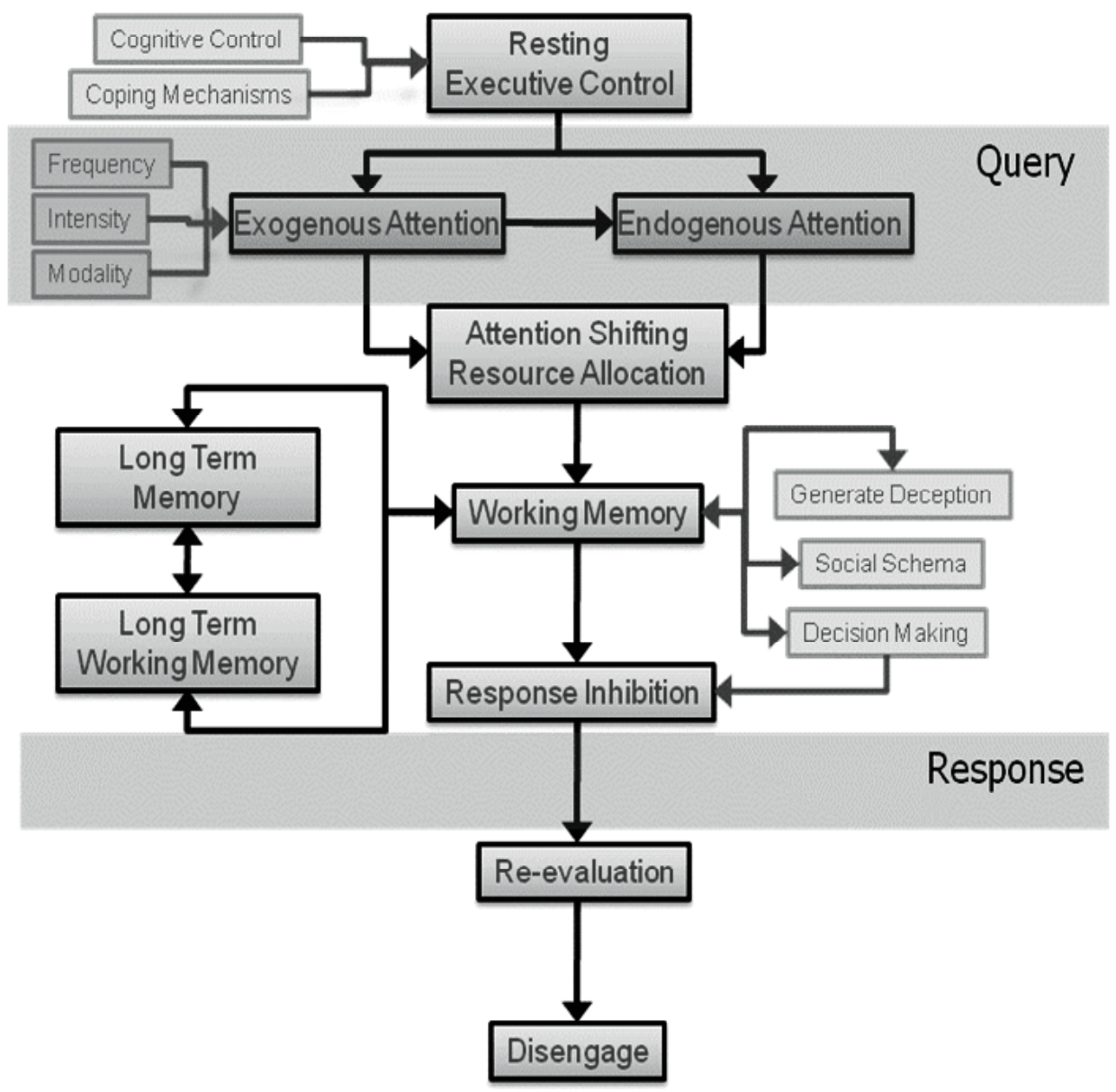

Figure 3. A cognitive framework for organizing studies of the processes involved in deception. 


\section{Studying Deception with an MRI}

As any examiner will note, the polygraph is not a tool for detecting deception, per se. The polygraph is a tool for measuring physiological responses. In the same way, a fMRI scan does not measure the brain activity unique to deception. While there is no one region of the brain that is directly associated with deception, there does seem to be a core set of cognitive processes that are associated with the processes involved in lie-telling. However, these processes are also associated with two levels of difficulty. Similar to the construction of a polygraph examination, a fMRI test must be constructed with attention to detail.

\section{What has fMRI told us about deception?}

Three papers have reviewed the data from fMRI studies of deception (Bhatt et al., 2009; Christ et al., 2009; Vendemia et al., 2009). Before discussing the studies, a quick note about anatomical names (see Figure 4). Neuroscientists have different preferences for naming cortical anatomy. The field is in a period of rapid growth, and we are learning previously unknown information about the brain. Naming conventions will continue to change as the breadth of our knowledge expands and our ability to map the brain improves. Some researchers have a preference for using Brodmann's Areas which represent numbered regions of the brain divided by the type of neurons in the region and their interconnections. Other researchers prefer a strictly anatomical name which is based soley on the structures of the brain. The third group has developed a merging of these naming systems to best represent what we know of the function of the underlying cortex. If you read literature about deception, you will most like see the structures in Figure 4.

Each of the reviews have focussed on the major studies in the field, and come to similar conclusions. The paradigms included modifed versions of the guilty knowledge task, lying about recently acquired knowledge, prepared or spontaneous lyies about past experiences, and lies about recent actions. Christ identified regional brain activity common across the studies in a metaanalysis, and then compared them to areas of the brain associated with three cognitive processes: 1) working memory, 2) inhibitory control, and 3) task switching. These three processes are most consistently reported throughout the deception literature and are supported by measures of reaction time, pupilommetry, galvanic skin response, and brain wave recordings obtained 

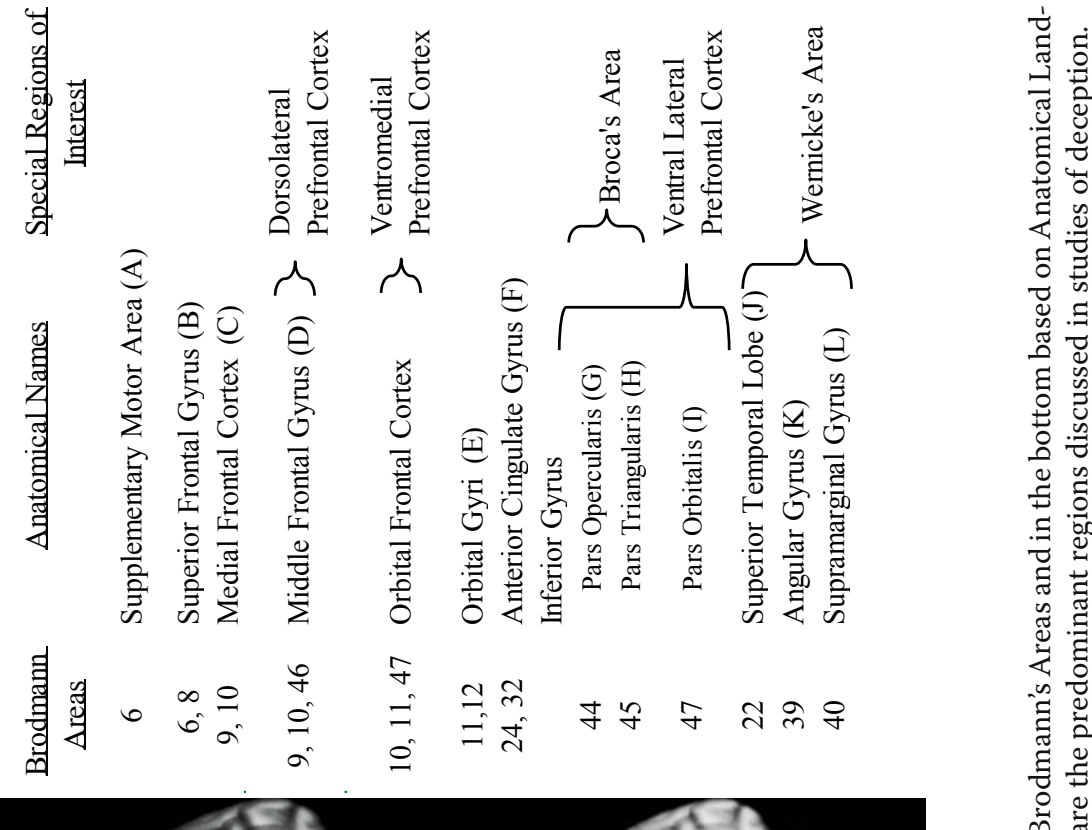

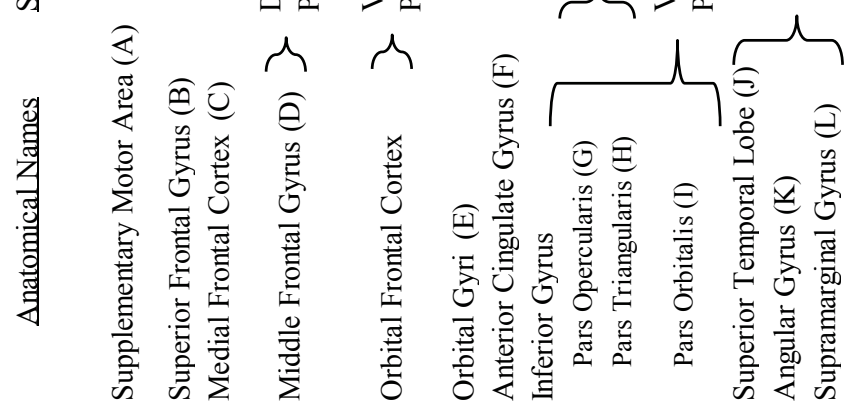


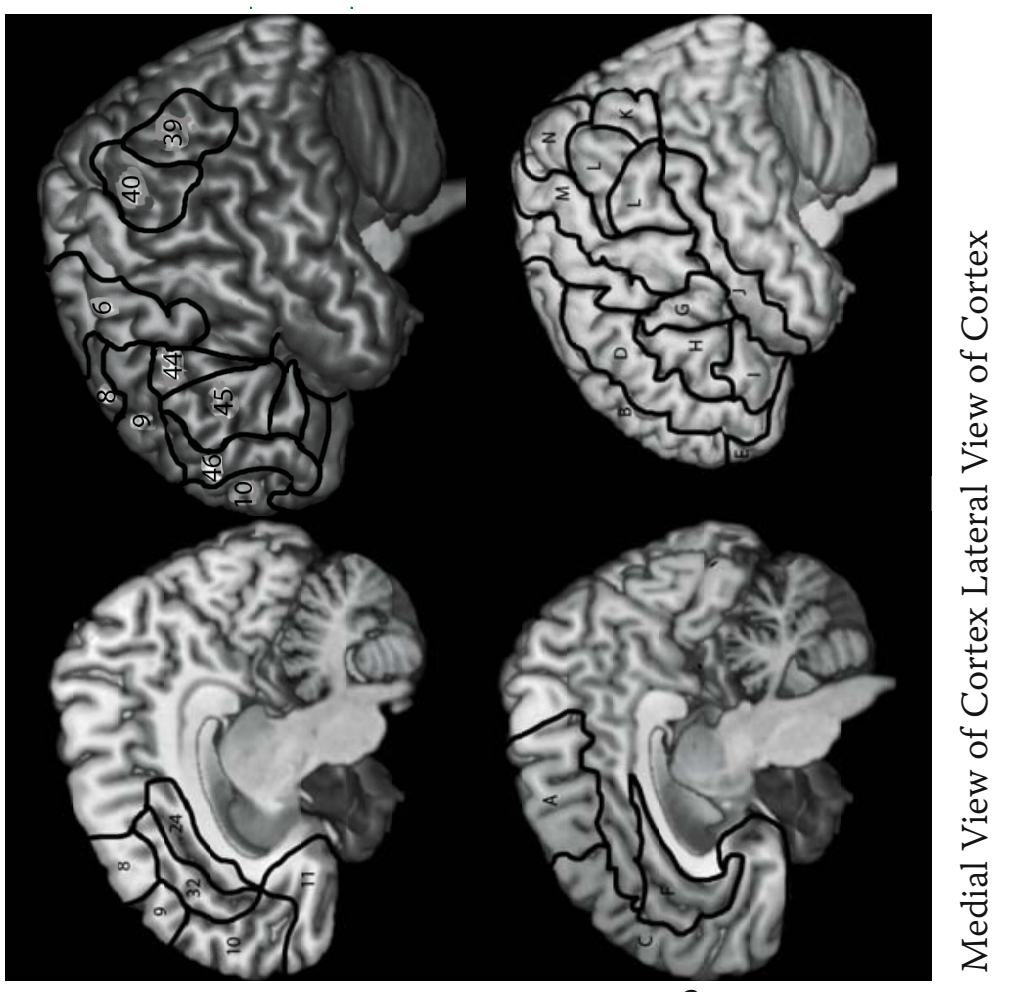

ตี

กิ

3.

ㅇํㅇ

Е

艺

U

虫

3 范

e)

$>\quad 0$

ปี่

$\stackrel{\square}{*}$

․․

के की

त्र

营 己

फ्ञ

3

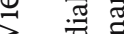

तี $\sum_{i}^{\infty}$

ت

$\sum^{0} \stackrel{0}{\Xi}$

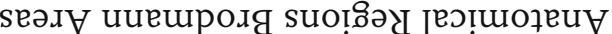


through event-related potentials (ERP). However, for reasons I will explain later the meta-analytic approach is not ideal with the research that has been conducted thus far.

In block design fMRI studies of deception, researchers have associated activations in the caudate (Lee et al., 2002), cerebellum (Ganis et al., 2003), cingulate (Mohamed, Faro, Gordon, Platek, Ahmad, \& Williams, 2006; Ganis et al., 2003; Kozel et al., 2004; Lee et al., 2002), cuneus (Ganis et al., 2003), fusiform/ parahippocampal area (Ganis et al., 2003; Kozel et al., 2004), precental gyrus (Ganis et al., 2003), ventrolateral prefrontal cortex (Mohamed et al., 2006; Spence et al., 2001), medial prefrontal cortex (Ganis et al., 2003; Langleben et al., 2002; Spence et al., 2001), prefrontal cortex (Mohamed et al., 2006; Ganis et al., 2003; Kozel et al., 2004; Lee et al., 2002), left frontal (Ganis et al., 2003; Langleben et al., 2002; Spence et al., 2001), left inferior parietal (Langleben et al., 2002), (Lee et al., 2002; Spence et al., 2001), and temporal, (Mohamed et al., 2006; Kozel et al., 2004; Lee et al., 2002; Stelmack, Houlihan, Doucet, \& Belisle, 1994b) regions with the act of deception.

Table 1 lists fMRI studies in which participants engaged in deceptive behavior or observed deceptive behavior, and the specifics of each paradigm. It is clear that these studies differ on how participants were "motivated" to deceive, the types of lies they were asked to tell, the type information about which they lied, and the type of polygraph scenario they attempted to parallel.

Table 1. A comparison of paradigms investigating deception

\begin{tabular}{|l|l|l|}
\hline Author & Paradigm Description & Lie Type \\
\hline $\begin{array}{l}\text { Bhatt et al., } \\
2009\end{array}$ & $\begin{array}{l}\text { Participants responded to grayscale images of faces } \\
\text { presented in lineups }\end{array}$ & $\begin{array}{l}\text { Facial recogni- } \\
\text { tion }\end{array}$ \\
\hline $\begin{array}{l}\text { Ganis et al., } \\
2003\end{array}$ & $\begin{array}{l}\text { Recorded work/vacation scenarios, after 1-week } \\
\text { delay generated alternate scenarios and memorized } \\
\text { them. }\end{array}$ & $\begin{array}{l}\text { Memorized and } \\
\text { Spontaneous }\end{array}$ \\
\hline $\begin{array}{l}\text { German et } \\
\text { al., 2004 }\end{array}$ & $\begin{array}{l}\text { Observers indicated whether real or acted clips re- } \\
\text { vealed completed acts. }\end{array}$ & Observation only \\
\hline $\begin{array}{l}\text { Grezes et } \\
\text { al., 2004 }\end{array}$ & $\begin{array}{l}\text { Observers indicated whether actors actually lifted } \\
\text { heavy boxes or pretended to lift heavy boxes. }\end{array}$ & Observation only \\
\hline $\begin{array}{l}\text { Kozel et al., } \\
2004 a\end{array}$ & $\begin{array}{l}\text { For a reward, participants lied and told the truth } \\
\text { regarding objects under which } \$ 50 \text { was hidden. }\end{array}$ & $\begin{array}{l}\text { Concealed infor- } \\
\text { mation }\end{array}$ \\
\hline $\begin{array}{l}\text { Kozel et al., } \\
2004 b\end{array}$ & $\begin{array}{l}\text { For a reward, participants, lied and told the truth } \\
\text { regarding an object under which } \$ 50 \text { was hidden. }\end{array}$ & $\begin{array}{l}\text { Concealed infor- } \\
\text { mation }\end{array}$ \\
\hline $\begin{array}{l}\text { Kozel et al., } \\
2005\end{array}$ & $\begin{array}{l}\text { For a reward, participants, lied and told the truth } \\
\text { regarding an object under which } \$ 50 \text { was hidden. }\end{array}$ & $\begin{array}{l}\text { Concealed infor- } \\
\text { mation }\end{array}$ \\
\hline $\begin{array}{l}\text { Langleben } \\
\text { et a., 2002 }\end{array}$ & Deception to cards in a concealed information test & $\begin{array}{l}\text { Concealed infor- } \\
\text { mation }\end{array}$ \\
\hline
\end{tabular}




\begin{tabular}{|c|c|c|}
\hline $\begin{array}{l}\text { Langleben } \\
\text { et al., } 2005\end{array}$ & $\begin{array}{l}\text { For a reward participants were instructed to (lie) } \\
\text { deny possession of one playing card and (truth) } \\
\text { acknowledge the possession of a different playing } \\
\text { card. }\end{array}$ & $\begin{array}{l}\text { Directed lie } \\
\text { about objects in } \\
\text { possession }\end{array}$ \\
\hline $\begin{array}{l}\text { Lee } \\
200 \\
\end{array}$ & $\begin{array}{l}\text { For a reward, participants lied in a card playing sce- } \\
\text { nario }\end{array}$ & aled infor- \\
\hline $\begin{array}{l}\text { Lee et al, } \\
2002\end{array}$ & $\begin{array}{l}\text { For an imaginary reward, participants faked amne- } \\
\text { sia to digits and autobiographical information }\end{array}$ & $\begin{array}{l}\text { Simulated am- } \\
\text { nesia digits and } \\
\text { autobiographic } \\
\text { memory }\end{array}$ \\
\hline $\begin{array}{l}\text { Mo } \\
\text { et a }\end{array}$ & t & \\
\hline $\begin{array}{l}\text { Nunez et } \\
\text { al., } 2005\end{array}$ & $\begin{array}{l}\text { Subjects instructed to give truthful or "false” an- } \\
\text { swers (blocked) to a series of yes/no questions that } \\
\text { also varied in autobiographical content }\end{array}$ & $\begin{array}{l}\text { Autc } \\
\text { cal } N\end{array}$ \\
\hline $\begin{array}{l}\text { Phan et al., } \\
2005\end{array}$ & $\begin{array}{l}\text { For a reward, participants lied in a card playing sce- } \\
\text { nario }\end{array}$ & $\begin{array}{l}\mathrm{Co} \\
\mathrm{ma}\end{array}$ \\
\hline $\begin{array}{l}\text { Spence et } \\
\text { al., } 2005\end{array}$ & $\begin{array}{l}\text { Participants were told to lie and tell the truth to } \\
\text { events that happened earlier in the day }\end{array}$ & $\begin{array}{l}\text { Directed lie to } \\
\text { episodic memory }\end{array}$ \\
\hline $\begin{array}{l}\text { Spence et } \\
\text { al., } 2001\end{array}$ & $\begin{array}{l}\text { Participants were told to lie and tell the truth to } \\
\text { events that happened earlier in the day }\end{array}$ & $\begin{array}{l}\text { Directed lie to } \\
\text { episodic memory }\end{array}$ \\
\hline
\end{tabular}

Even given these differences, activations in certain regions could be anticipated based on the underlying processes engaged in each study. For example, the studies by Kozel et al. (2004, 2004b, 2005), Langleben et al. (2002), and Phan et al. (2005) each used a risk-taking scenario in which participants would receive a monetary reward if they "fooled" the examiner, but no reward if they failed to "fool" the examiner. Given this condition, activation could be anticipated in the orbitofrontal cortex, a region of the frontal cortex that has been implicated in the integration of motivational stimuli when guiding response selection (Schoenbaum, Takahashi, Liu, \& McDannald, 2011). Only Kozel identified activation in this region.

John Gabrieli and other fMRI researchers argue that the anterior prefrontal cortex, or Brodmann's Area 10, is involved in the act of deception (Gabrieli, July 14, 2005). Ramnani and Owen (2004) argue that this area is activated when an individual must make simultaneous considerations of multiple relations. When an individual deceives, these multiple relations may occur between situational context, goal-driven behavior, divergence of the deceptive information from truthful information, and a variety of internal states. Given the generalist nature of these "simultaneous considerations," it is no surprise that several researchers have identified activation in this region during the 
act of deception (Bhatt et al., 2009; Ganis et al., 2003; Lee et al., 2002; Mohamed et al., 2006; Vendemia, \& Buzan, 2004a; ).

However, the most widely reported region of activation is the anterior cingulate (Vendemia, \& Buzan, 2004b; Spence et al., 2001). This activation is broken down into two main areas, the ventral anterior cingulate and the dorsal anterior cingulate. Some researchers believe that this area is involved in conflict resolution, while others believe that it is involved in attention shifting and resource allocation processes. It is possible that the more ventral regions are involved in conflict resolution, while the more dorsal area is involved in attention shifting. It is theoretically probable that the act of deception involves both processes.

Bhatt's (2009) review of the brain regions activated in fMRI studies noted that the group activations reported in the studies were quite varied (activation between truthful groups and deceptive groups). Vendemia et al., (2009) evaluated the intersubject variability between the studies finding that the general differences in brain activation between participants was greater than that between truthful and deceptive responding. At first the variability seems overwhelming, but this variability is exactly what research with the fMRI is designed to identify.

The polygraph is a reliable measure of autonomic nervous system responses, and it is very robust. Any variety of test formats produce similar results, even though the formats measure different aspects of cognition, attention, and emotion. The reason the tests are robust is that autonomic system responses result from the combination of cognitive processes. Very similar patterns of results can be the results of different combinations of cognitive processes. For example, the guilty knowledge ("concealed information") test depends on the presentation of the infrequent "relevant" item among high frequency irrelevant items. Extensive research with the infrequent/frequent paradigm with other measures of cortical activity suggest that "the expectation of the infrequent stimulus" drives the autonomic system activity. When the anticipated infrequent stimulus occurs and the rare information is recognized a particular brainwave, the oddball P300, occurs (Allen \& Iacono, 1997; Allen et al., 1992; Farwell \& Donchin, 1991; Rosenfeld et al., 1999). Particular cognitive functions associated with the identification of the infrequent stimulus include attention resource allocation (Comerchero \& Polich, 1999), and the consequential updating of information held in working memory (Donchin \& Coles, 1988; Ruchkin et al., 1990).

During probable lie format exams, in which relevant questions are embedded in between pairs of "probably lie" questions that are then intermingled with irrelevant questions, waveforms associated with recall of information 
(N4) and switching between high and low difficulty conditions occur (Meek, Phillips, Boswell, \& Vendemia, 2013; Schillaci \& Vendemia, 2014; Vendemia, Schillaci, Buzan, Green, \& Meek, 2009).

Using fMRI, along with other technologies and techniques, we can begin to parcel the specific cortical activity that occurs during the act of deception. The task is far from simple, and the studies conducted thus far are rife with errors in test construction. They repeat errors that occurred in the early 1990's with the first studies of brain wave measures of deception which repeated errors in the first designs of polygraph tests. In addition to errors in design, fMRI tests are susceptible to a variety of errors.

\section{Problems with fMRI studies of Deception}

Noise related to people. Within subject noise can occur any time a subject moves inside the MRI scanner. Respiratory and cardiac artifacts can also create within subject noise during scans, as can attentional modulation, changes in cognitive strategy, drugs and medications, anxiety, and countermeasures. Factors related to within subject noise are also consistently present in between subject noise. Whenever a difference occurs between participants that is not related to the task, it enters into a class of error called between subject noise. Variability in how the brain's anatomy, differences in hemoglobin concentrations, cytoarchitectonic variability (how the different parts of the brain are connected during development), and variability in venous drainage patterns are all factors of between subjects noise. Other factors such as how much information a person can maintain at any given moment in time, working memory, are also considered between subject noise if the experimenter has not considered them.

An example of the impact of such a variable can be observed in a study in which we tested the verbal memory in 19 participants who then performed a deception task in the fMRI.

All were scans collected at 3T with Siemens Magnetom Trio System using T2* weighted echoplanar images sensitive to blood oxygen levels were acquired during the functional scans (gradient echo; $T R=2490 \mathrm{~ms} ; T E=30$ $\mathrm{ms}$; image matrix $=64 \mathrm{X} 64$; in-plane resolution $=208 \mathrm{X} 208 \mathrm{~mm}$; slice thickness $=3.2 \mathrm{~mm}$ ). Voxel-wise analysis was carried out using flexible hemodynamic response function (HRF) modeling, allowing HRF to vary spatially and between subjects. (Woolrich 2004). Analysis was carried out using FEAT (FMRI Expert Analysis Tool) Version 5.63, part of FSL (FMRIB's Software Library, www.fmrib.ox.ac.uk/fsl). Time-series statistical analysis was car- 
ried out using FILM with local autocorrelation correction (Woolrich 2001). $\mathrm{Z}$ (Gaussianised T/F) statistic images were thresholded using clusters determined by $\mathrm{Z}>2.3$ and a (corrected) cluster significance threshold of $\mathrm{P}=0.05$ (Worsley 1992). Registration to high resolution and/or standard images was carried out using FLIRT (Jenkinson 2001, 2002).

Participants with lower scores on verbal working memory had greater relative activation in the left middle frontal gyrus while responding deceptively than those with higher scores (Figure 5). The finding is critical as the left middle frontal gyrus is a common finding in fMRI studies of deception. If participants who have poor working memory skills show greater activation in deception relative to truth telling than any study that reports left frontal middle activation without accounting for the effect verbal working memory is potentially confounded.

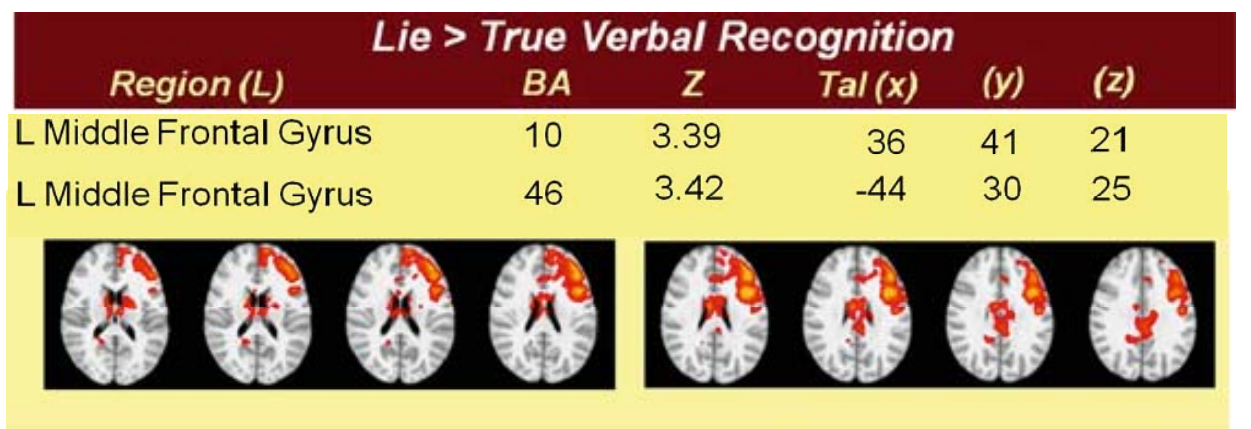

Figure 5. Greater relative left middle frontal gyrus activation in participants with lower working memory scores than those with higher working memory scores when they respond deceptively as compared to truthfully.

Paradigm Noise. Issues with between paradigm noise arise from inconsistent definitions of types of deception being used in paradigms, differences in stimuli presented (rate, number, and type), differences in the type of memory involved, and differences in reward/punishment scenarios. We studied a very simple aspect of stimulus presentation in the fMRI by having participants respond deceptively on different percentages of the trials.

Participants were 89 undergraduate college students (61 females, Mean age $=20.9$ yrs, $\mathrm{SD}=3.45)$. Ethnicity breakdown : 78\% Caucasian, $8 \%$ AfricanAmerican, 3\% Asian, 2\% Hispanic, 3\% identified as Other, 5\% did not report. An event-related paradigm was implemented with 200 trials of the twostimulus type being presented. Participants were randomly assigned to one of three conditions, $20 \%$ Lie $(\mathrm{N}=15), 50 \%$ Lie $(\mathrm{N}=21)$, or $80 \%$ Lie $(\mathrm{N}=21)$. 
These N's represent the final numbers, as participants were thrown out for too much motion or accuracies below $85 \%$ before analyses.

As can be seen in Figure 6 relative activity in the anterior cingulate and parietal cortex was significantly greater when participants responded on $50 \%$ of the trials as compared to $20 \%$ of the trials. Activity in the anterior cingulate is the primary finding in fMRI studies of deception. The effect of this small paradigm manipulation has crucial implications. First, it is critical to know what is the mechanism causes anterior cingulate action. Second researchers must be clear about how frequently participants told lies; of the previous research studies reviewed for this paper several did not contain enough information to determine how often their participants told lies. Of those papers in which the information was available the participants were deceptive on $10 \%$ to $80 \%$ of trials.

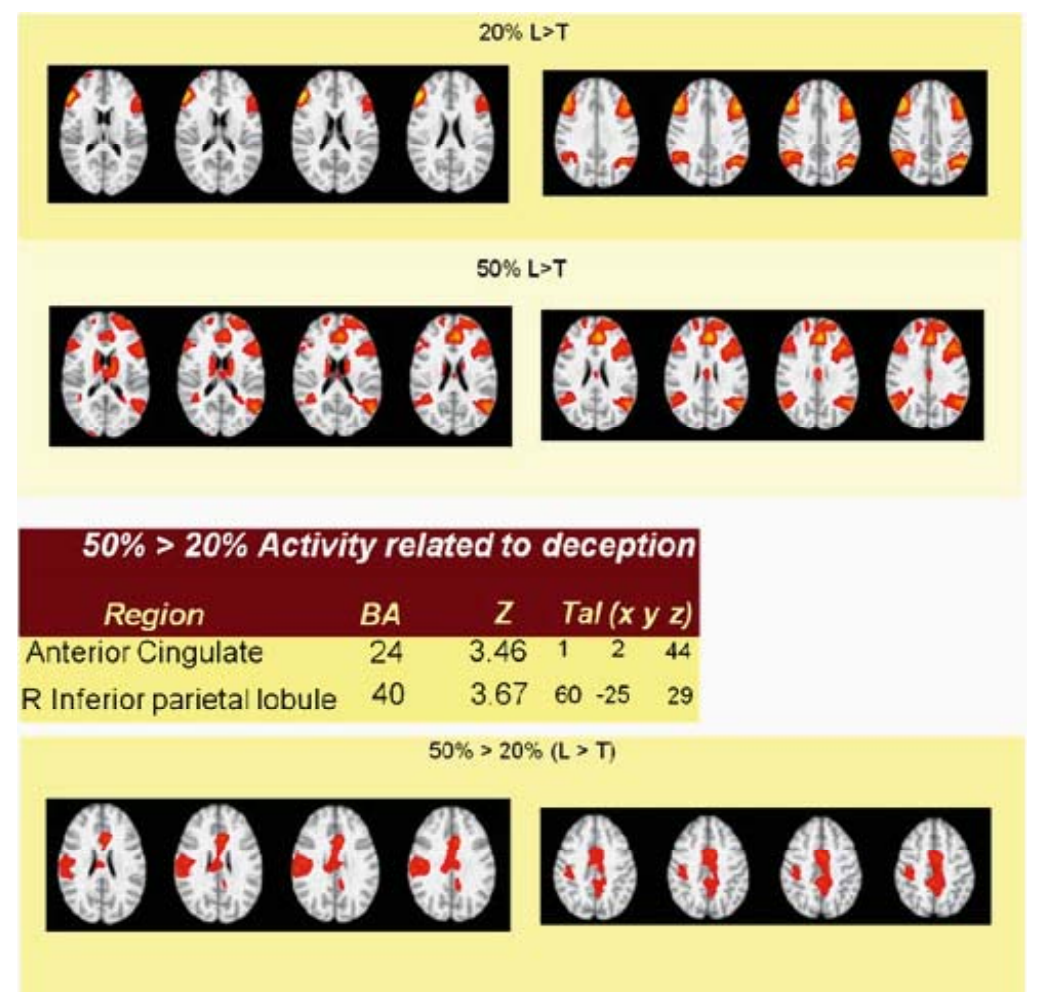

Figure 6. Patterns of relative brain activation when participants respond deceptively as compared to truthfully. In the top panel, participants responded deceptively on $20 \%$ of the trials. In the second panel participants responded deceptively on $50 \%$ of the trials. The bottom panels shows the specific regions that were activated more in the $50 \%$ condition than in the $20 \%$ condition. 
Validity of Stimuli. Deception paradigms are based on the assumption that the only difference between stimulation "questions" is the participant's truthful, deceptive, or unknown response. A substantial body of scientific evidence points to several confounding factors within the question set designs of existing paradigms (Phillips, Meek, \& Vendemia, 2011). Unfortunately, a systematic approach to question design based on known linguistic and cognitive principles has not been developed (Phillips \& Vendemia, 2008). The validity of test stimuli should be investigated thoroughly by basic researchers, rather than applied researchers, and then tested for generalizability and disseminated to the field.

Analytical Assumptions. fMRI is a multivariate signal which means that the brain functions as a system with different areas of activation being interdependent on one another. The problem of multivariate signal detection can be easily resolved by requiring that researchers utilize multivariate approaches for data analysis or reduction. In some cases a univariate approach can be justified, and for those, researchers should be able to provide such justification. All levels of research, from basic validity testing to field testing, should meet this criterion.

Methodological Confounds. Researchers should be familiarized with the literature of deception before they begin constructing paradigms. Methodological confounds can enter the test scenario at any level of research or field design. A mechanism should be put into place to allow feedback between basic and applied researchers to communicate possible sources of confounds. In addition, a mechanism should be put into place that allows field examiners to communicate to appropriate applied researchers when the field applications provide unexpected results.

Unity of Construct Assumption. A basic research program that focuses on the identification of models of deception and of underlying dimensions of deception should exist. This program is a fundamental part of establishing the validity of the measures.

Construct Validity. An ongoing basic research program that focuses on the identification of a valid model of deceptive behavior at the central nervous system should exist. If a valid model can be identified with central nervous system measures, then test designs can be formulated based on those measures and translated to other sensor systems for experimental testing. 


\section{Conclusions}

fMRI has the potential for yielding the most specific measures of deceptive behaviors of any technology; however, that potential is significantly hampered by a lack of specificity in the current research applications. A major problem with the current set of research protocols is that researchers are often guided by unidimensional theoretical assumptions, without any consideration of confounding factors. This is particularly problematic because the reported studies are highly confounded by variables known to affect peripheral system measures (and therefore CNS measures as well).

Researchers need to be familiar with neuroscientific processes in the human brain to conduct adequate studies with this technology. Of critical importance is a familiarity with those processes known to affect other dependent measures of deception. Test construction within this arena is of paramount importance. Researchers need to have experience with the broad set of results and techniques in the field of credibility assessment, and to revisit questions many times before reaching conclusions.

\section{References}

Abe, N., Okuda, J., Suzuki, M. S., Matsuda, T., Mori, E., Tsukada, M., et al. (2008). Neural correlates of true memory, false memory, and deception. Cerebral Cortex, 18, 2811-2819.

Abe, N., Suzuki, M., \& Tsukiura, T. (2006). Dissociable Roles of Prefrontal and Anterior Cingulate Cortices in Deception. Cerebral Cortex, 16, 192-199.

Allen, J.J., Iacono, W.G., Danielson, K.D. (1992). The identification of concealed memories using the event-related potential and implicit behavioral measures: A methodology for prediction in the face of individual differences. Psychophysiology, 29, 504-522.

Allen, J.J.B., Iacono, W.G. (1997). A comparison of methods for the analysis of event-related potentials in deception-detection. Psychophysiology, 34, 234-240.

Basile, B., Bozzali, M., Macaluso, E., \& Mancini, F. (2009). Neural correlates of altruistic and deontological guilt: An fMRI investigation in healthy individuals. Behavior Therapy, 17, 3974. 
Bhatt, S., Mbwana, J., Adeyemo, A., Sawyer, A., Hailu, A., \& Vanmeter, J. (2009). Lying about facial recognition : An fMRI study. Brain and Cognition, 69(2), 382-390.

Christ, S. E., Van Essen, D. C., Watson, J. M., Brubaker, L. E., \& McDermott, K. B. (2009). The contribution of prefrontal cortex and executive control to deception: Evidence from activatin likelihood estimate meta analyses. Cerebral Cortex, 19(7), 1557-1566.

Farwell \& Donchin, 1. (n.d.).

Gamer, M., Bauermann, T., Stoeter, P., \& Vossel, G. (2007). Covariations among fMRI, skin conductance, and behavioral data during processing of concealed information. Human Brain Mapping, 28(12), 1287-1301.

Ganis, G., Kosslyn, S. M., Stose, S., Thompson, W. L., \& Yurgelun-Todd, D. A. (2003). Neural correlates of different types of deception: an fMRI investigation. Cerebral Cortex, 13(8), 830-836.

Greene, J. D., \& Paxton, J. M. (2009). Patterns of neural activity associated with honest and dishonest moral decisions. Proceedings of the National Academy of Sciences of the United States of America, 106(30), 12506-12511.

Iacono, A. \&. (1997).

Johnson, R., Barnhardt, J., \& Zhu, J. (2004). The contribution of executive processes to deceptive responding. Neuropsychologia, 42(7), 878-901.

Johnson, R., Barnhardt, J., \& Zhu, J. (2005). Differential effects of practice on the executive processes used for truthful and deceptive responses: an eventrelated brain potential study. Cognitive Brain Science, 24(3), 386-404.

Kozel, F. A., Johnson, K. a., Grenesko, E. L., Laken, S. J., \& George, M. S. (2005). Detecting deception using functional magnetic resonance imaging. Biological Psychiatry, 58(8), 605-613.

Kozel, F. A., Padgett, T. M., \& George, M. S. (2004). A replication study of the neural correlates of deception. Behavioral Neuroscience, 118, 851-856.

Kozel, F. A., Revell, L. J., Lorberbaum, J. P., Shastri, A., Elhai, J. D., \& Horner, M. D. (2004). A pilot study of functional magnetic resonance imaging brain correlates of deception in healthy young men. Journal of Neuropsychiatry and Clinical Neuroscience, 16, 295-305. 
Langleben, D. D., Loughead, J. W., Bilker, W. B., Ruparel, K., \& Childress, A. R. (2005). Telling truth from lie in individual subjects with fast eventrelated fMRI. Human Brain Mapping, 26, 262-272.

Langleben, D. D., Schroeder, L., Maldjian, J. A., Gur, R. C., McDonald, S., \& Ragland, J. D. (2002). Brain activity during simulated deception: An eventrelated functional magnetic resonance study. NeuroImage, 15, 727-732.

Lee, T. M., Liu, H., Tan, L., Chan, C. C., Mahankali, S., Feng, C., et al. (2002). Lie Detection by Functional Magnetic Resonance Imaging. Human Brain Mapping, 15, 157-164.

Lee, T., Liu, H., Chetwyn, C., Ng, Y., Fox, P., \& Gao, J. (2005). Neural correlates of feigned memory impairment. NeuroImage, 28, 305-313.

Meek, S. W., Phillips, M. C., Boswell, C. P., \& Vendemia, J. M. (2013). Deception and the misinformation effect: An event-related potential study. International Journal of Psychophysiology, 87 (1), 81-87.

Mohamed, F., Faro, S., Gordon, N., Platek, S., Ahmad, H., \& Williams, J. (2006). Brain mapping of deception and truth telling about an ecologically valid situation: Functional MR imaging and polygraph invstigation-initial experience. Radiology, 238, 679-688.

Nunez, J. M., Casey, B. J., Egner, T., Hare, T., \& Hirsch, J. (2005). Intentional false responding shares neural substrates with response conflict and cognitive control. NeuroImage, 25, 267-277.

Phan, K. L., Magalhaes, A., Ziemlewicz, T. J., Fitzgerald, D. A., Green, C., \& Smith, W. (2005). Neural correlates of telling lies: A functional magnetic resonance imaging study at 4 Tesla. Academic Radiology, 12, 164-172.

Phillips, M. C., \& Vendemia, J. M. (2008). Individual differences in comparison question anxiety. European Polygraph, 2, 5-6.

Phillips, M. C., Meek, S. W., \& Vendemia, J. M. (2011). Understanding the underlying structure of deceptive behaviors. Personality and Individual Differences, 50(6), 783-799.

Ramnani, N., \& Owen, A. M. (2004). Anterior prefrontal cortex: Insights into function from anatomy and neuroimaging. Nature, 5, 184-194.

Rosenfeld, J. P., Ellwanger, J., Nolan K., Wu, S., Bermann, R. G., Sweet, J. P300 scalp amplitude distribution as an index of deception in a simulated cognitive deficit model. International Journal of Psychophysiology, 33, 3-19. 
Sanchez, C., Meek, S., Phillips, M., Craig, A., \& Vendemia, J. (2007). Anterior Cingulate and Prefrontal Activity as Correlates of Attention Switching and Consideration of Multiple Relations during Truthful and Deceptive Responses: A BOLD Imaging Study. The 12th annual meeting of the Cognitive Neuroscience Society. New York, NY.

Schillaci, M., \& Vendemia, J. M. (2014). ERP Energy and Cognitive Activity Correlates. Bulletin of the American Physical Society.

Schoenbaum, G., Takahashi, Y., Liu, T., \& McDannald, M. (2011). Does the orbitofrontal cortex signal value. Annals of the New York Academy of Sciences, 1239, 87-99.

Smith, S. W., Jenkinson, M., Woolrich, M. W., Beckmann, C. F., Behrens, T. E., \& Johansen-Berg, H. (2004). Advances in functional and structural MR image analysis and implementation as FSL. NeuroImage, 23(S!), 208-219.

Spence, S. A., Farrow, T. F., Green, R. D., Leung, D. H., Hughes, C. J., \& Ganeson, V. (2004). A cognitive neurobiological account of deception; Evidence from function neuroimaging. Philosophical Transaction of the Royal Society B: Biological Sciences, 359, 1755-1752.

Spence, S. A., Farrow, T. F., Herford, A. E., Wilkinson, I. D., Zheng, Y., \& Woodruff, P. W. (2001). Behavioural and functional anatomical correlates of deception in humans. Neuroreport, 12, 2849-2853.

Vendemia, J. M., Schillaci, M. J., Buzan, R. F., Green, E. P., \& Meek, S. W. (2009). Alternate technologies for the Detection of Deception. In D. Wilcox (Ed.), The Use of the Polygraph in Assessing, Treating and Supervising Sex Offenders: A Practitioner's Gude (267-296). West Sussex, UK: Wiley \& Sons, Ltd.

Yokota, S., Taki, Y., Hashizume, H., Sassa, Y., Thyreau, B., Tanaka, M., et al. (2013). Neural correlates of deception in social contexts in normally developing children. Frontiers in Human Neuroscience, 7, 1-8. 